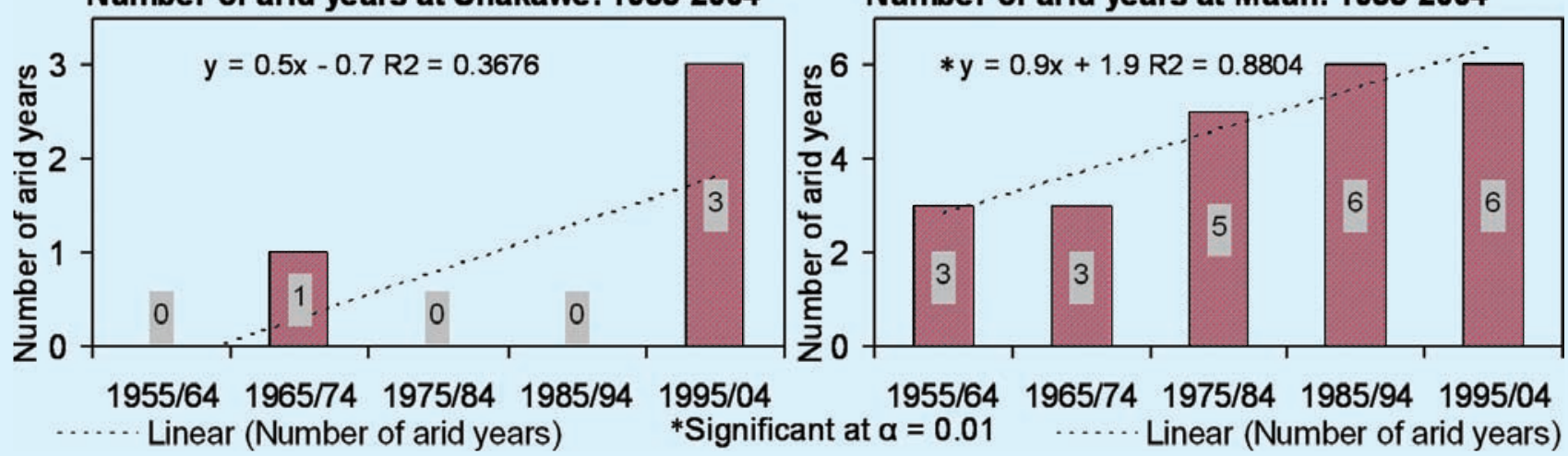

Figure 2: Frequency of arid years by decade period for Shakawe and Maun: 1955-2004.

evidence comes from trends in mapped vegetation distribution during the second half of the 20th century. In the proximal, intermediate and distal reaches of the Okavango Delta, recent changes in vegetation distribution have been characterized by transitions from reed-swamps and open grassland to woody cover dominated by drought tolerant species (Hamandawana, 2006). Between 1967 and 2001, woody cover around Shakawe and Mohembo increased by $20 \%$ while open grassland declined by $15 \%$ with these trends being statistically significant at $a=0.01$ and 0.05 respectively. In the intermediate reaches around Gumare, woody cover significantly increased by $26 \%(a=0.05)$ as open grassland declined by $43 \%(a=0.01)$. In the distal reaches around Sehitwa, Acacia mellifera increased by $21 \%$ while open grassland declined by $5 \%$ with both trends being statistically significant at $a=0.01$. These changes are indicative of climatedriven responses to progressive decrease in local rainfall, which has tended to selectively facilitate the expansion of woody cover at the expense of drought-sensitive wetland and dryland grasses. Though this area's climate is widely classified as semiarid ((Aridity Index (AI) $=0.20-<0.50)$ ), analysis of available data shows increasing frequency of arid years ( $\mathrm{Al}=0.05-<0.20$ ) for successive decades between 1955 and 2004 (Fig. 2).

This shift from semi-arid to arid conditions is consistent with current climate change scenarios that point to mid-continent drying in southern Africa, centered on Botswana, due to the increasing incidence of rainfall failures. In view of the pervasive nature of drying sequences during the recent past, the need for formulating appropriate policies designed to mitigate the adverse effects of deteriorating climatic conditions is now overdue. With evidence suggesting that these sub-regional trends are likely to persist, deployment of appropriately informed adaptation strategies designed to enhance human capacities to cope with deteriorating climate conditions are urgently required. Adoption of effective strategies requires official acknowledgement of the non-transient character of the present direction of change. Thus the onus is on climate change science to inform policy formulation by providing long-term perspectives.

\section{References}

Campbell, A. and Child, G., 1971: The impact of man on the environment of Botswana, Botswana Notes and Records, 3: 91-109.

Chapman. J., 1886: Travels in the interior of South Africa, Bell and Daldy: Reprinted A.A. Balkema, Cape Town, 1971.

Hamandawana, H., Eckardt, F. and Chanda, R., 2005: Linking archival and remotely sensed data for long-term environmental monitoring, International Journal of Applied Earth Observation and Geoinformation, 7(4): 284-298

Hamandawana, H., 2006: An investigation of the role of human factors in the degradation of natural resources in and around the Okavango Delta, Ph.D. Thesis, Department of Environmental Science, University of Botswana.

Hamandawana, H., Chanda, R. and Eckardt, F., in press. Reappraisal of contemporary perspectives on climate change in southern Africa's Okavango Delta sub-region, Journal of Arid Environments.

Stigarnd, A. G., 1922: Sketch maps of Ngamiland and Ghanzi: Plan BP-122 and BP-123. Department of Surveys and Mapping, Gaborone.

\title{
Sensitivity of wetlands and water resources in south- eastern Australia to climate and catchment change
}

\section{Peter Gell ${ }^{1}$, R. Jones ${ }^{2}$ and A. MacGregor ${ }^{1}$ \\ ${ }^{1}$ Geographical \& Environmental Studies, University of Adelaide, Australia; peter.gell@adelaide.edu.au ${ }^{2} \mathrm{CSIRO}$ Marine \& Atmospheric Research, Aspendale, Australia.}

Southeastern Australia lies within a temperate zone characterized by mild, but wet winters and hot summers with low ratios of precipitation:evaporation (P/E). Reconstructions of paleosalinity and water level from numerous crater lakes (e.g. Lake Keilambete) provide the means to monitor long-term changes to $\mathrm{P} / \mathrm{E}$, and have revealed a regional pattern of Holocene climate change (Bowler, 1981; Chivas et al., 1985; Gell, 1998; Jones et al., 1998). These records witness humid conditions and overflowing lakes in the mid-Holocene, a rapid decrease in moisture at $5.5 \mathrm{kyr}$ BP followed by a gradual trend to a variable and drier climate at c. 3 kyr BP. From c. 2.2 kyr BP the lakes refilled, though not to the midHolocene levels. These lakes are therefore sensitive to changes in P/E on the scale of centuries to millennia but appear insensitive to short-term climate variability. In contrast, the diatom-inferred paleosalinity records from numerous fluviatile lakes across southeastern Australia across this period do not reveal the same sensitivity to long-term changes in climate. For exam- ple, along the River Murray, Tareena Billabong experiences mid-Holocene freshness followed by increased connectivity to the River (Gell et al., 2005) but then a sustained period of stability until the arrival of European settlers C. $1840 \mathrm{AD}$. In the Coorong, a large back-barrier lagoon at the mouth of the River Murray system, stratigraphic and diatom evidence reveals relative resilience (Fluin et al., in press) to the P/E changes documented in the sensitive crater lakes to the east. Still further east in the coastal plain of the Snowy River, a diatom salin- 


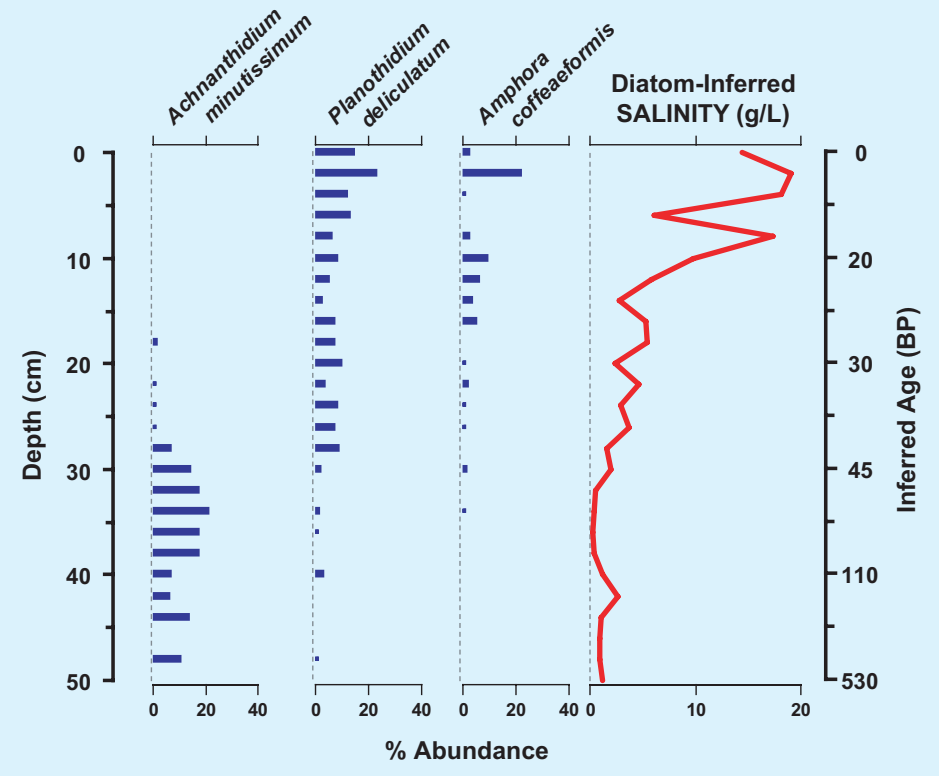

Figure 1: Summary diagram of Lake Curlip Fossil Diatom Record (adapted from MacGregor et al., 2005).

ity reconstruction (MacGregor et al., 2005) shows a strong geomorphic control on water source but little of the variation in Lake Keilambete that would suggest a climatic cause. These 3 records suggest that the water balance response to climatic fluctuations, in water bodies within fluviatile environments, is much more rapid. Therefore, the 2 sets of water bodies respond to climate fluctuations on different timescales.

More recently, high lake levels were recorded in Lake Keilambete in 1859 but from this time a decline in $\mathrm{P} / \mathrm{E}$ in the order of $15 \%$ has seen this 'rain gauge' lose $75 \%$ of its volume (Jones et al., 2001). This change, which occurred in all rain-fed crater lakes in the region, was not due to human intervention in landscape processes. However, in floodplain settings, processes resulting from catchment modification do appear to dominate the records of inferred water quality from wetlands. For example, in the lower Snowy River the salinity of Lake Curlip has increased 50-fold (Fig. 1), mostly owing to the transfer of $98 \%$ of the Snowy River's mean flow to the River Murray catchment (MacGregor et al., 2005). The Murray-Darling Basin (MDB) itself provides $40 \%$ of Australia's agricultural gross domestic product largely driven by an irrigation agriculture industry that consumes the majority of the $80 \%$ of its flow diverted for human use. The diatom flora of over 30 cores analyzed along the Murray-Murrumbidgee River floodplains attest to widespread salinization, eutrophication and increases in sedimentation rate and water turbidity. Very recently, elevated nutrients have combined with drought to oxidize accumulated sulfides, thus inducing wetland acidification (Gell et al., 2006). In all cases, the diatom flora in the base of cores is in contrast to that in the upper sediments demonstrating that no pre-impact, or reference, wetlands exist within the subset studied. In most cases, the recent flora is unprecedented within the record demonstrating the wetlands of the Murrumbidgee and Murray River floodplains are in a no-analogue state.

From these studies we can assert that several wetlands have been subjected to multiple stressors, sometimes coincidentally. This is attributed to the causal co-variation between several drivers and stressors on the system that has seen the widespread impacts of overgrazing, rising saline groundwater, regulation, abstraction and severe drought (Fig. 2). This includes the link between sediment supply, turbidity and eutrophication and between salinization, sodicity and soil erosion. Thus, these catchment change stressors are inter-related, are moderated by climate, and are ongoing and evolving into wetland conditions that are both unprecedented and unexpected in a lowland, carbonate landscape.

Projections of P/E under climate change suggest ongoing desiccation across the
MDB, particularly in the southeast uplands that have historically provided the bulk of streamflow (Jones et al., 2002). This, in concert with the decline in effective rainfall documented from the mid-19th century, represents a phase of desiccation that, in both magnitude and rate, is unprecedented since the earliest Holocene. Future reductions in streamflow of $5-25 \%$ in the southern temperate-zone channels of the catchment are projected by 2030 (Jones and Durack, 2005), possibly exceeding $50 \%$ by mid-century (Fig. 3 ). While reduced P/E will lower water tables reducing salt flux, the reduced flow will see a net increase in stream salinity. Commitments by the Australian Government to return $500 \mathrm{GL} / \mathrm{yr}$ as environmental flows to restore MDB wetlands are unlikely to keep pace with climate change. Models of water yield from the Bet Bet Creek subcatchment in Victoria suggest that widespread revegetation, targeted to mitigate climate change through carbon sequestration (which will also slow groundwater rise and stabilize soil surfaces), will exacerbate climate-driven desiccation (Zhang et al., 2005).

The last decade has seen historically unprecedented low flows in a number of catchments, including the MDB (Dreverman, 2006). These changes are of a magnitude similar to those projected for 2030. It remains unclear whether these signify: 1) a short-term random fluctuation; 2) the first significant shifts in rainfall as part of climate change; 3 ) part of ongoing longer-term natural variability; or 4) some combination of (2) and (3). The evidence suggests the latter is most likely. As the recent decline is unlikely to be a short-term fluctuation in climate variability, a return to the prevailing moister conditions that prevailed during the period 1946-1996 is the least likely of all plausible alternatives. The highly contested nature of water allocations within the catchment and the increasing influence of climate change on water availability, suggests that the current

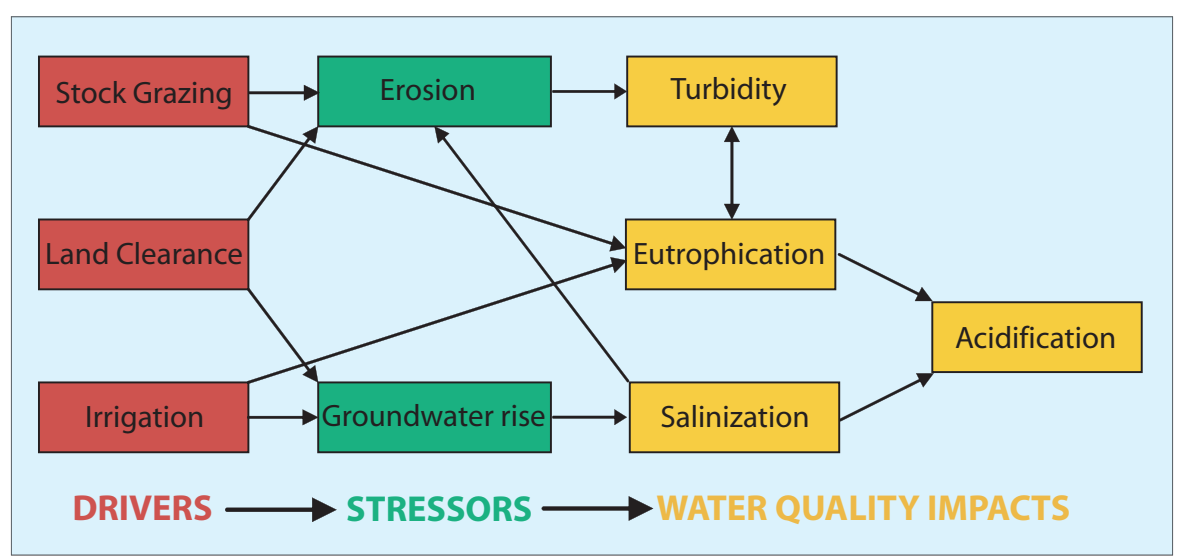

Figure 2: Flow diagram of interactions between drivers and stressors to Murray-Darling Basin wetlands. 


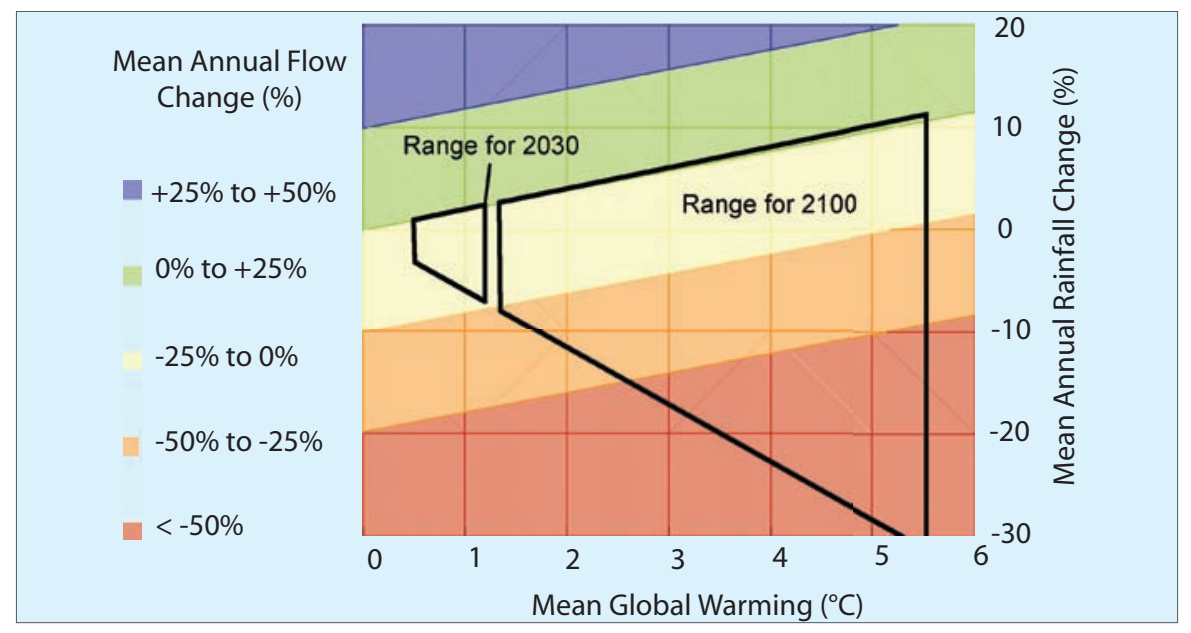

Figure 3: Murray Darling Basin runoff response to warming and rainfall change.

bulk allocations of surface water are unsustainable. Abstraction and climate change, along with catchment modification leading to high water tables and degraded water quality, represent serious threats to the capacity to rehabilitate floodplain wetlands to a healthy, functioning state. Measures to adapt to climate change must be sensitively implemented. Environmental al- locations need not relate solely to volume, but also to variability and timing, so that various uses are favored differently from one year to the next. The widespread and timely adoption of water use efficiencies is essential to avoid both long-term deleterious effects to aquatic ecosystems and to maintain an irrigation industry that is a significant provider of food to Australia and elsewhere. Without increased efficiencies, the trade-off of continued water use and land practices under a drying climate is to risk placing all lowland MDB wetlands beyond the reach of restoration to any natural condition defined by its past experience.

\section{References}

Jones, R.N. Bowler, J.M and McMahon, TA, 1998: A high resolution Holocene record of $\mathrm{P} / \mathrm{E}$ ratio from closed lakes in Western Victoria, Palaeoclimates, 3: 51-82.

Gell, P., Bulpin, S., Wallbrink, P., Bickford, S. and Hancock, G., 2005: Tareena Billabong - A palaeolimnological history of an everchanging wetland, Chowilla Floodplain, lower Murray-Darling Basin, $\mathrm{Ma}$ rine and Freshwater Research, 5: 441-456.

MacGregor, A.J., Gell, P.A., Wallbrink, P.J. and Hancock, G., 2005: Natural and post-disturbance variability in water quality of the lower Snowy River floodplain, Eastern Victoria, Australia, River Research and Applications, 2: 201-213.

Jones, R. N., McMahon, T. A. and Bowler, J. M., 2001: Modelling historical lake levels and recent climate change at three closed lakes, Western Victoria, Australia (c.1840-1990), Journal of Hydrology, 246: 159-180.

Jones, R.N., Whetton, P.H., Walsh, K.J.E. and Page, C.M., 2002: Future impacts of climate variability, climate change and land use change on water resources in the Murray Darling Basin: overview and draft program of research, Murray Darling Basin Commission, Canberra, ACT, 27 pp

For full references please consult:

www.pages-igbp.org/products/newsletters/ref2007_1.html

\section{The rise and fall of atmospheric pollution: The paleolimnological perspective}

\section{NeIL Rose}

Environmental Change Research Centre, University College London, UK; nrose@geog.ucl.ac.uk
The catchments of remote mountain lakes often comprise sensitive geologies and sparse soils and these factors, in combination with severe meteorology, conspire to produce fragile ecosystems. Anthropogenic impacts in these areas are limited to long-range transported pollutants and large-scale effects such as climate change, but despite their isolation from direct contamination, the additional stress of atmospheric pollutant deposition often results in detectable chemical and/or biological change. Remote lakes can, therefore, act as 'early warning' indicators for less sensitive sites and as a result they have become a useful tool in monitoring the impacts of atmospherically deposited pollutants. Recent studies in Europe have shown that long-range transported pollutants have been impacting remote lakes for hundreds of years and that this deposition can result in the accumulation of both trace metals and persistent organic pollutants in biota sometimes to significant levels. The lake sediment record of remote lakes provides the temporal dimension to such observations. In remote regions long-term monitoring is often absent and so paleolimnology provides a means to determine directions of change (i.e. deterioration or improvement) as well as, via reliable chronologies, rates of these changes. Such information thus provides a historical context for contemporary measurements as well as a base-line against which to measure future impacts.

Paleolimnological records of pollutants from remote lakes have been produced from many areas of the world and consistently show significant increases in pollutant deposition in agreement with historical trends in industrial activities on regional and international scales. However, if we assume that the sediment record can faithfully record the past trends in anthropogenic emissions to the atmosphere then it must also be the case that these lake sediments will record the decline in pollutant emissions observed in many industrialized countries since the 1970's. In some cases such reductions have been dramatic, for example, declines of over $80 \%$ and $75 \%$ for mercury $(\mathrm{Hg})$ and lead $(\mathrm{Pb})$ in the UK respectively. However, our studies at Lochnagar in Scotland have shown that while there have been considerable reductions observed in the emissions of metals to the UK atmosphere, and similar reductions recorded in the metal content of deposition across the country, the total amount of metal entering the loch and recorded in the sediments remains almost unchanged since the 1950's (e.g., Pb: Fig. 1). As atmospheric deposition is known to have declined, this 'additional' metal can only be derived from previously deposited contamination being released from storage within the sparse catchment soils.

A number of hypotheses have been proposed to explain this observation (Rose et al., 2004). First, that this is due to a simple time-lag effect, i.e. metals deposited onto the catchment take a number of years to work through to the water body and thus the enhanced catchment inputs now observed are the result of high metal deposition decades ago. Second, increased erosion of the contaminated levels of catchment soils (possibly resulting from the effects of increased drought or episodes of high rainfall) are bringing the catchmentstored metals into the lake.

At Lochnagar, as in many areas of Scotland, there is significant catchment peat 